\title{
Genetic mismatch affects the immunosuppressive properties of mesenchymal stem cells in vitro and their ability to influence the course of collagen- induced arthritis
}

Catherine Sullivan ${ }^{1}$, J Mary Murphy', Matthew D Griffin', Ryan M Porter², Christopher H Evans², Cathal O'Flatharta', Georgina Shaw ${ }^{1}$ and Frank Barry ${ }^{1^{*}}$

\begin{abstract}
Introduction: The immunological and homing properties of mesenchymal stem cells (MSCs) provide a potentially attractive treatment for arthritis. The objective of this study was to determine effects of genetic disparity on the immunosuppressive potential of MSCs in vitro and in vivo within collagen induced arthritis (CIA).

Methods: The ability of DBA/1, FVB and BALB/C MSC preparations to impact the cytokine release profile of CD3/ CD28 stimulated DBA/1 T cells was assessed in vitro. The effect of systemically delivered MSCs on the progression of CIA and cytokine production was assessed in vivo.

Results: All MSC preparations suppressed the release of TNF $\alpha$ and augmented the secretion of IL-4 and IL-10 by stimulated DBA/1 T-cells. However, assessment of the ratio of IFN $\gamma$ to IL-4 production indicated that the more genetically distant BALB/C MSCs had significantly less immunosuppressive capacity. Systemic delivery of BALB/C MSC resulted in an exacerbation of CIA disease score in vivo and a higher erosive disease burden. This was not seen after treatment with syngeneic or partially mismatched MSCs. An increase in serum levels of IL-1 $\beta$ was observed up to 20 days post treatment with allogeneic MSCs. An initial elevation of IL-17 in these treatment groups persisted in those treated with fully mismatched BALB/C MSCs. Over the course of the study, there was a significant suppression of serum IL-17 levels in groups treated with syngeneic MSCs.
\end{abstract}

Conclusions: These data demonstrate a significant difference in the immunosuppressive properties of syngeneic and allogeneic MSCs in vitro and in vivo, which needs to be appreciated when developing MSC based therapies for inflammatory arthritis.

\section{Introduction}

Rheumatoid Arthritis (RA) is characterized by systemic inflammation and local synovitis with pannus formation. The inflamed synovium is populated with CD4+ T lymphocytes, B cells, macrophages and synovial like fibroblasts which elaborate pathophysiologically important cytokines including TNF $\alpha$, IL-1, IL-4, IL-10 and IL-17 [1-3]. While numerous cells are involved in disease the ongoing activation of $\mathrm{T}$ cells is central in perpetuating

\footnotetext{
* Correspondence: frank.barry@nuigalway.ie

'Regenerative Medicine Institute, National University of Ireland Galway, University Road, Galway, Ireland

Full list of author information is available at the end of the article
}

tissue inflammation and damage through stimulation of mesenchymal cells, including chondrocytes and fibroblasts [2]. Early studies demonstrating the central role of TNF $\alpha$ have been translated into the development of blocking drugs which have revolutionized the treatment of RA [4]. Despite recent advances and wide availability of anti-TNF agents, a considerable number of patients remain refractory to treatment [5-7]. Other therapeutic strategies include B cell depletion, inhibition of $\mathrm{T}$ cell co-stimulation and anti IL-6 receptor antibodies $[8,9]$.

While TNF $\alpha$ produced by macrophages is at the center of a complex cytokine network in inflammatory arthritis, it is well established that CD4+ $\mathrm{T}$ cells play an important

\section{C) Biomed Central}


role in orchestrating and maintaining this immune response. The production of Th1 cytokines in animal models is associated with arthritis induction and inflammation and collagen induced arthritis (CIA) is a Th1 driven disease, while Th2 cytokines are found during disease remission [10]. However, the role of IFN $\gamma$ in CIA is complex with a peak in early disease and evidence of a disease limiting role in late disease decreasing IL-17 production and osteoclast precursors while increasing the activity of T regulatory cells [11]. IL-17 is produced by a subset of memory CD4+ T lymphocytes termed Th17 cells and plays a critical role in CIA, having a synergistic effect with TNF $\alpha$ in promoting poor disease outcome [12-14]. IL-1 $\beta$ has also been implicated in both RA and CIA; it is known to have a pro-inflammatory role in CIA which is independent of IL-17 and inhibition with an IL1 receptor antagonist results in amelioration of arthritis $[15,16]$. The role of anti-inflammatory cytokines in CIA is less clear; however, IL-4 can inhibit production of TNF $\alpha$ and reduce $T$ cell proliferation [2].

There is considerable interest in bone marrow derived mesenchymal stem cells (MSCs) which have the capacity to differentiate into cells of the connective tissue compartment including bone, cartilage and fat. Both mouse and human MSCs are known to have immunosuppressive effects on $\mathrm{T}$ and $\mathrm{B}$ cells in vitro [17-20] and this is likely to be an important aspect of their mode of action. MSCs can inhibit proliferation of $\mathrm{CD} 4^{+}$and $\mathrm{CD} 8^{+} \mathrm{T}$ cells in a dose-dependent manner independently of major histocompatibility complex (MHC) matching with reduced expression of activation markers $[21,22]$. The mechanisms underlying this immune suppression are not fully understood and may be mediated by transforming growth factor- $\beta$, hepatocyte growth factor, IL-10 or prostaglandin-E2 produced by the cells [21,23,24]. Additionally, MSC immune regulation may be mediated through secondary effects on other cells, such as increased TNF $\alpha$ and IL-10 production by dendritic cells and decreased IFN $\gamma$ production by Th1 cells [25-27].

In vitro studies suggest that the immunosuppressive properties of MSCs may be useful for in vivo treatment of inflammatory arthritis [28]. MSCs from healthy donors can inhibit type II collagen (CII) stimulated proliferation of $\mathrm{T}$ cells from arthritis patients [29]. In addition, adipose derived stem cells (ASC) can exert profound suppressive responses on CII-reactive $\mathrm{T}$ cells by suppressing CIIinduced $\mathrm{T}$ cell proliferation, inhibiting inflammatory cytokine production and stimulating production of IL-10 by monocytes and T cells. Co-culture of ASCs with $\mathrm{T}$ cells induced the generation of antigen-specific $\mathrm{T}$ regulatory cells and ASCs were also shown to inhibit production of inflammatory factors by activated synovial cells involved in the destruction of cartilage and bone [30]. Overall, it is clear that MSCs exert immunosuppressive effects on several classes of lymphocytes through mechanisms that may be exploited in a clinical setting. As MSCs may migrate to sites of injury in vivo it is feasible to suggest that targeting of the cells to inflamed joints might have a therapeutic effect on local arthritis through MSC-mediated immunosuppression [31,32]. An additional property of MSCs is their status as immune privileged cells with low expression of MHC II [33,34] and an absence of co-stimulatory molecules $[21,35]$. This raises the prospect of allogeneic cell therapy in a variety of disease models. However, translation of compelling in vitro data to pre-clinical studies of arthritis has resulted in conflicting data [30,36-41]. Studies using either single or multiple injections of MSCs have shown varying degrees of disease amelioration or exacerbation. MSCs have been delivered at various time points, including at disease induction or during established disease, and generally at doses of $1 \times 10^{6}$ cells, although in some cases up to $5 \times$ $10^{6}$ cells. In an effort to shed further light on the diseasemodifying effects of allogeneic MSC transplantation, we looked at the effects of genetic disparity between systemically delivered MSCs and the host recipient. We hypothesized that the degree of mismatch between donor and host may exert a profound effect on their immunosuppressive properties. We studied this in vitro by examining the interactions between MSCs and T cells when the cells were syngeneic, partially mismatched or fully mismatched. We achieved this by examining the effects of MSCs from DBA/1 mice on T cells from the same strain (syngeneic), from FVB mice (partially mismatched) and from BALB/c mice (fully mismatched). For in vivo studies we considered it important to establish if the genetic background affected the ability of a single injection of MSCs at the time of onset of clinical disease to alter disease progression in CIA.

\section{Materials and methods}

\section{Mesenchymal stem cell isolation and characterization}

MSCs were isolated from the bone marrow of eight- to ten-week old BALB/c and FVB mice as described previously [42]. For DBA/1 mice collagenase digestion of the marrow was carried out before MSC expansion in complete expansion medium (Iscove's modified eagle's medium, 9\% horse and 9\% fetal bovine serum (FBS), 1\% penicillin and streptomycin $(\mathrm{P} / \mathrm{S}), 1 \% \mathrm{~L}$-glutamine; $\mathrm{CEM})$. It has been demonstrated that murine bone marrow derived MSCs isolated using collagenase digestion retain the characteristic properties of MSC [43]. Briefly, mononuclear cells from two femurs were plated in a T-175 flask. Sufficient fibroblastic-like cells were obtained at the end of P1 to replate at 50 cells $/ \mathrm{cm}^{2}$ and 4,500 cells $/ \mathrm{cm}^{2}$ were plated for subsequent passages with about a 10 -fold increase in cell number by confluency (seven days). Expression of cell surface antigens was 
quantified using flow cytometry. Briefly, 200,000 cells were used per antibody staining. After blocking in PBS with $2 \%$ FBS, $1 \%$ rat serum for 30 minutes on ice, cells were centrifuged at $400 \mathrm{~g}$ for 5 minutes and resuspended in $100 \mu$ of the appropriate antibody diluted in PBS with $2 \%$ FBS. CD73, CD34 and CD31 antibodies were used at 1:200, Sca1, CD105, CD44 and CD29 at 1:400 and CD45 at 1:500. Cells were incubated on ice for 30 minutes in the dark, washed in PBS with 2\% FBS and resuspended in $200 \mu \mathrm{l}$ prior to analysis on the BD FACS Canto flow cytometer. All antibodies were from eBioscience (Hatfield, UK) except for anti-CD45 (Becton Dickinson, Franklin Lakes, NJ, USA). All MSC preparations were stimulated to undergo adipogenesis, osteogenesis and chondrogenesis as described previously using CEM as the basal medium for osteogenesis and adipogenesis [44]. Adipogenesis was confirmed with Oil Red O staining for lipid vacuoles. Osteogenesis was assessed using quantitation of calcium with the Calcium Liquicolour Kit (StanBio, Boerne, TX, USA) and mineral deposition visualized using alizarin red. For chondrogenesis cell pellets were digested with papain and glycosaminoglycan (GAG) was determined using the dimethylmethylene blue assay. Histological sections $(5 \mu \mathrm{M})$ of formalin-fixed pellets were stained for the presence of GAG using toluidine blue.

\section{Collagen induced arthritis}

All animal work was carried out with approval from the local Institutional Animal Care and Use Committee. Male mice seven- to nine-weeks old were used for all arthritis induction as female DBA/1 mice are not susceptible to CIA. Mice were obtained from a commercial supplier and housed in groups of two or three; room temperature and food, water supply and general health were assessed daily. There were 12 mice included in each CII treatment group. CIA was induced in male DBA/1 mice by immunization with $50 \mu \mathrm{L}$ bovine bovine CII emulsified in $50 \mu \mathrm{L}$ complete Freund's adjuvant followed by a booster immunization in incomplete adjuvant at 21 days. MSCs from eight- to ten-week old mice at passage four to six were delivered intravenously on day 21 via the lateral tail vein; $1 \times 10^{6}$ MSCs were suspended in $100 \mu \mathrm{l}$ of PBS and used within 30 minutes of preparation. Cell counts using trypan blue exclusion of dead cells confirmed $>95 \%$ cell viability for MSCs harvested and stored by these methods for all three strains (results not shown). A control group received PBS. Clinical scores were calculated based on the paw thickness across the metatarsophalangeal joints and dactylitis as follows: paw $<2 \mathrm{~mm}=$ 0 points, paw 2 to $3 \mathrm{~mm}=2$ points, paw 3 to $4 \mathrm{~mm}=3$ points, paw 4 to $5 \mathrm{~mm}=4$ points, paw 5 to $6 \mathrm{~mm}=5$ points, swollen wrist or ankle $=3$ points, swollen digit $=$ 1 point. The scoring system ensured that disease activity reflected by dactylitis only was not overlooked and avoided reliance on measurement in increments $<1 \mathrm{~mm}$ and subjective assessment of erythema. The clinical score was assessed every 24 hours. Blood was collected and serum cytokine levels assayed using a Bio-Plex 200 cytokine array. Knees were fixed in formalin, processed, paraffin-embedded, sectioned and stained with a modified Mallory stain [45].

\section{In vitro $T$ cell stimulation studies}

Spleens and submandibular lymph nodes from DBA/1 mice were harvested, placed in ice-cold PBS/10\% FBS, shredded and passed through a $70 \mu \mathrm{m}$ mesh. A combination of splenic and nodal cells were harvested to optimize cell numbers and approximately $20 \times 10^{6}$ cells were isolated per mouse; for each experiment cells from three DBA/1 mice were mixed. The resulting single cell suspension was centrifuged at $120 \mathrm{~g}$ for 10 minutes and resuspended in lysis buffer (Invitrogen, Dublin, Ireland). After three minutes incubation at room temperature, cold $\mathrm{PBS} / 2 \% \mathrm{FBS}$ was added and the sample centrifuged for 10 minutes. Cells were washed in PBS/2\% FBS and either resuspended in medium (HG-DMEM, 10\% FBS, $2 \% \mathrm{P} / \mathrm{S}, 1 \%$ HEPES, $12 \mu \mathrm{M}$ L-glutamine and $1 \%$ non essential amino acids) or used for $\mathrm{T}$ cell isolation.

$\mathrm{CD} 4^{+} \mathrm{T}$ cells were isolated by positive selection using murine CD4 Dynabeads (Miltenyi Biotech, Bergisch Gladbach, Germany). Cells were resuspended in MACS buffer with CD4 microbeads and CD4- cells were separated on an octoMACS magnetic separator (Miltenyi Biotech) according to the manufacturer's instructions. The $\mathrm{CD} 4^{+}$cells were resuspended in DMEM/10\% FBS and stimulated with anti-CD3/anti-CD28 beads (1:1 ratio) (Dynabeads mouse $\mathrm{T}$ cell expander, Invitrogen) for 24 hours in 96-well tissue culture plates. The activated $\mathrm{T}$ cells were washed and $1 \times 10^{5} \mathrm{~T}$ cells were replated with adherent MSCs (passage four to six, six donor mice), at an MSC:CD4 cell ratio of 1:10 or 1:1, and re-stimulated by the same method. The re-activation of $\mathrm{T}$ cells at the time of addition to MSC cultures was designed to mimic the in vivo scenario where mice received the booster immunization which triggers overt inflammation at the time of MSC delivery. Culture supernatants were collected at 24 hours for determination of cytokine concentrations by ELISA (eBioscience Mouse Th1/Th2 and Mouse TNF $\alpha$ ELISA Sets).

\section{Statistics}

Statistical analysis was performed using StatsDirect ${ }^{\circledR}$ software. In all instances the Shapiro Wilks test was used to confirm a normal distribution. For direct comparisons t-tests or Mann Whitney tests were used where appropriate for parametric/non-parametric data, respectively. Comparison between groups was carried out using analysis of variance (ANOVA) with post-hoc Tukey testing. 


\section{Results}

\section{MSC isolation}

MSCs were isolated from bone marrow of DBA/1, FVB and BALB/c mice. DBA/1 and FVB mice carry the MHC $\mathrm{H} 2^{\mathrm{q}}$ haplotype while BALB/c mice carry the $\mathrm{H} 2^{\mathrm{d}}$ haplotype. All three MSC strains had a characteristic fibroblastic morphology and were differentiated under appropriate conditions into chondrocytes, adipocytes and osteocytes. Although adipogenesis and chondrogenesis were similar between all three strains, FVB cells had the highest osteogenic potential. All three MSCs preparations were over 95\% positive for CD29 and CD44. Detection of CD105 and Sca 1 varied between strains as has been shown previously [42] with approximately $17 \%$ of BALB/c MSCs positive for CD73. All three strains of MSCs were negative for CD45, CD34 and CD31 (Figure 1, Table 1) [20,35,42,46]. Cells also lacked expression of MHC II (results not shown).

\section{In vitro cytokine $\mathrm{T}$ cell studies}

TNF $\alpha$ and IFN $\gamma$ were detected in the supernatant of $\mathrm{CD}^{+}{ }^{+} \mathrm{T}$ cells 24 hours post-stimulation with CD3/CD28 beads. Only trace levels were measured in the supernatants from unstimulated T cells with and without MSCs, and cultures containing only MSCs (results not shown). The secretion of TNF $\alpha$ by stimulated $\mathrm{CD}^{+} \mathrm{T}$ cells was significantly suppressed by all MSC preparations at ratios of $1: 10$ and 1:1 (Figure 2A). Syngeneic (DBA/1) and partially mismatched (FVB) MSCs did not significantly affect IFN $\gamma$ secretion by DBA/ $1 \mathrm{CD}^{+} \mathrm{T}$ cells at 24 hours (Figure 2B). Similarly, fully mismatched BALB/ c MSCs did not alter IFN $\gamma$ levels at a ratio of 1:10; however, there was a significant increase in IFN $\gamma$ production by $\mathrm{T}$ cells co-cultured with mismatched MSCs at the higher ratio of 1:1 (Figure 2B).

IL-4 secretion by stimulated $\mathrm{CD}^{+} \mathrm{T}$ cells was detected at 24 hours. This was significantly increased in cultures with MSCs from each genetic background at the $1: 1$ ratio. With a lower MSC to $\mathrm{CD}^{+} \mathrm{T}$ cell ratio of 1:10 only syngeneic MSCs increased IL- 4 secretion; this was significantly higher than IL-4 detected in cultures containing either mismatched MSC at this ratio. With the exception of partially mismatched MSCs at a ratio of 1:10, all MSCs increased IL-10 production by stimulated $\mathrm{T}$ cells after 24 hours (Figure 2D).

The ratio of Th1:Th2 cytokine production was determined based on IFN $\gamma$ and IL-4 levels. After 24 hours this Th1:Th2 ratio was reduced in cultures containing syngeneic and partially mismatched MSC demonstrating a shift towards Th2 production compared to controls; this was significant at the higher cell ratio of 1:1 (Figure 2E). There was no significant difference between Th1:Th2 ratio of $\mathrm{T}$ cells cultured with fully mismatched (BALB/c) MSCs compared to controls at either the $1: 10$ or 1:1 MSC:T cell ratio. However, there was a significant difference between the Th1:Th2 cytokine ratio of $\mathrm{T}$ cells co-cultured with BALB/c MSCs compared to that of either the syngeneic or partially mismatched cultures (Figure 2E).

In all groups, controls of un-stimulated CD4+ T cells with and without MSCs were included; no production of pro or anti-inflammatory cytokines was seen in these groups (results not shown).

\section{MHC mismatch influences the effect of murine MSCs on disease progression in $\mathrm{CIA}$}

CIA was induced in male DBA/1 mice by immunization with bovine IIC. Twenty-one days later a booster immunization was given along with an intravenous dose of MSCs, either syngeneic, partially matched or mismatched. Clinical scores were calculated based on the paw thickness across the metatarsophalangeal joints (Figure 3D) and dactylitis (Figure 3E); all mice developed obvious signs of arthritis. The systemic delivery of syngeneic MSCs had no effect on disease progression in CIA when compared to mice receiving vehicle control alone (Figure 3A). The delivery of $\mathrm{H}-2$ matched allogeneic FVB MSCs appeared to worsen disease progression but this was not statistically significant (Figure 3B). However, infusion of allogeneic $\mathrm{H}-2$ mismatched BALB/ c MSCs resulted in significantly higher disease scores when compared to vehicle controls from day nine postbooster to the end of the experiment (Figure 3C). Histological evidence of erosive disease in the paw, ankle and knee joints of mice with CIA has been demonstrated previously $[38,47]$. In the present study knee joints were examined histologically to assess for inflammatory disease not evident on clinical examination and $95 \%$ of all knees analyzed had evidence of histological synovitis. Furthermore, erosive disease was demonstrated in 50\% of mice receiving vehicle control, syngeneic or partially mismatched MSCs compared to $70 \%$ of mice receiving fully mismatched BALB/c MSCs (Figure 4B and 4D). This difference did not reach statistical significance and the mean clinical scores between erosive and non-erosive groups were similar (results not shown). Evidence of erosive disease was also found following histological examination of the interphalangeal joint of the paw (Figure 4F and 4G).

Serum was collected 7 and 20 days after booster immunization and cytokine levels were analyzed. Serum TNF $\alpha$ levels were elevated in CIA mice treated with vehicle only compared to non-arthritis controls. There was no significant difference in TNF $\alpha$ levels between treatment groups or compared to vehicle controls (Figure 5A). At day seven levels of IFN $\gamma$ were increased in mice receiving MSCs from all genetic backgrounds. This effect was transient and there was no significant difference between groups at 

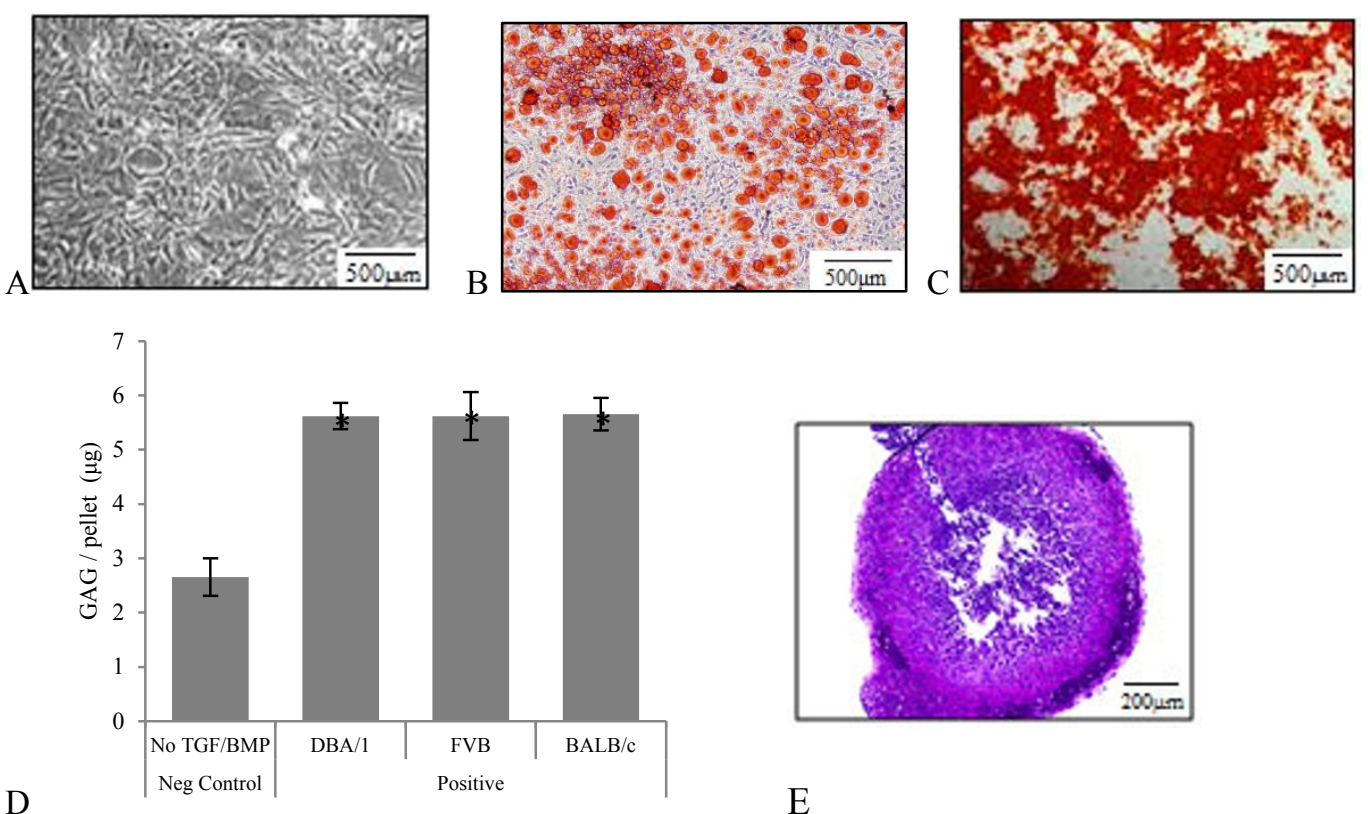

E

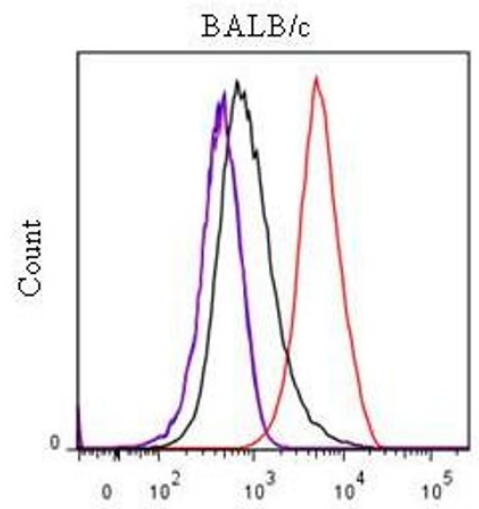

F
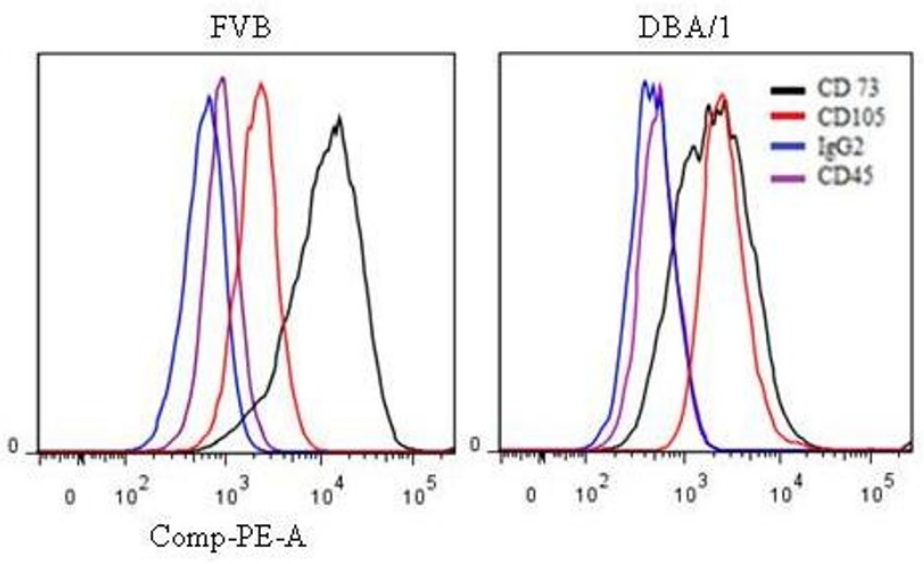

$\mathrm{BALB} / \mathrm{c}$

FVB

$\mathrm{DBA} / 1$
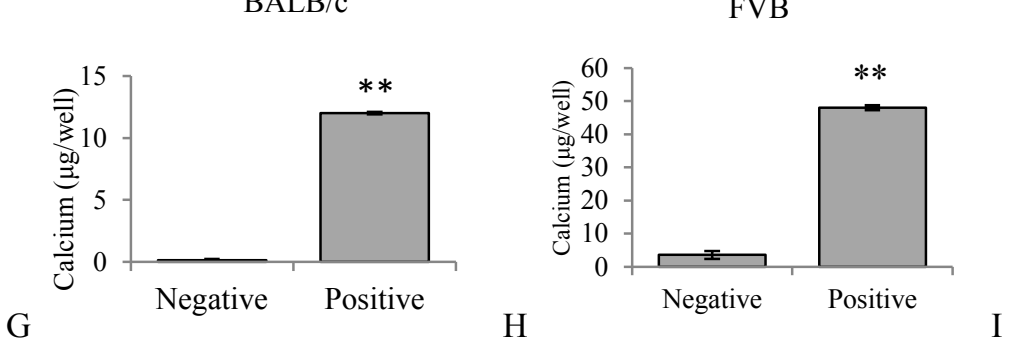

$\mathrm{H}$

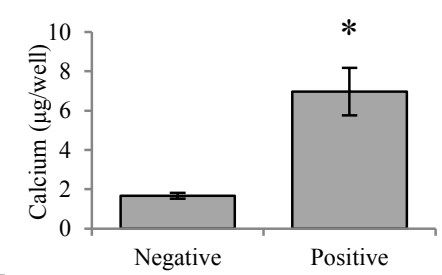

Figure 1 Mouse MSC characteristics. Representative images of BALB/C MSCs showing $\mathbf{A}$, fibroblastic morphology of MSCs, B, adipogenesis with fat vacuoles stained with Oil Red $O$ and C, osteogenesis with Alizarin Red staining (scale $500 \mu \mathrm{m})$. D, proteoglycan (GAG) per $10^{5}$ cell pellet demonstrating chondrogenic potential in the presence of TGF 33 and BMP2. Analysis was performed in triplicate pellets; * $P<0.05$ (Mann

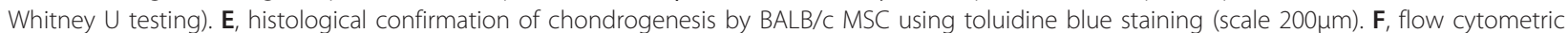
analysis of BALB/C, FVB and DBA/1 MSCs showing them to be positive for CD73 and CD105, and negative for CD45. G, H, I, calcium deposition demonstrating osteogenesis; ${ }^{*} P<0.05,{ }^{* * P}<0.001$ (unpaired $T$ test). Data represents mean \pm standard deviation of triplicate cultures. BMP, bone morphogenetic protein; GAG, glycosaminoglycan; MSC, mesenchymal stem cells; TGF $\beta$, transforming growth factor beta. 
Table 1 Bone marrow stromal cells from all three mouse strains had characteristics of mesenchymal stem cells in terms of morphology, differentiation capacity and cell surface markers.

\begin{tabular}{|c|c|c|c|}
\hline Mouse Strain & DBA/1 & FVB & $\mathrm{BALB} / \mathrm{c}$ \\
\hline MHC H2 Haplotype & $\mathrm{H} 2^{q}$ & $\mathrm{H} 2^{\mathrm{q}}$ & $\mathrm{H} 2^{\mathrm{d}}$ \\
\hline Morphology & Fibroblastic & Fibroblastic & Fibroblastic \\
\hline Adipogenesis & Positive & Positive & Positive \\
\hline $\begin{array}{l}\text { Osteogenesis }^{a} \\
(\mu \mathrm{g} \mathrm{Ca/well)}\end{array}$ & $6.9 \pm 1.6$ & $48.0 \pm 0.9$ & $11.9 \pm 0.2$ \\
\hline 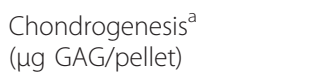 & $5.6 \pm 0.3$ & $5.6 \pm 0.5$ & $5.6 \pm 0.3$ \\
\hline $\mathrm{CD}_{73}^{\mathrm{b}}$ & 64.8 & 97 & 17.2 \\
\hline $\mathrm{CD} 105^{\mathrm{b}}$ & 82 & 49.5 & 97.9 \\
\hline Sca $1^{b}$ & 89.9 & 67.5 & 53 \\
\hline CD29 & 99.2 & 99.4 & 96.2 \\
\hline CD44 & 95.1 & 98.7 & 99.7 \\
\hline $\mathrm{CD} 45^{\mathrm{b}}$ & 0.6 & 4 & 0.6 \\
\hline $\mathrm{CD} 34^{\mathrm{b}}$ & 0.4 & 0.4 & 0.8 \\
\hline $\mathrm{CD} 31^{\mathrm{b}}$ & 0.4 & 0.5 & 1.3 \\
\hline
\end{tabular}

${ }^{a}$ Data represents mean \pm standard deviation of triplicate assays; ${ }^{b} \%$ positive cells; GAG, glycosaminoglycan; MHC, major histocompatibility complex.

20 days (Figure $5 \mathrm{~B}$ ). At seven days IL-1 $\beta$ was elevated in all treatment groups compared to controls. This persisted in the serum of mice treated with either FVB or BALB/c MSCs. However, serum levels in mice treated with either PBS or syngeneic MSCs were lower than those treated with allogeneic MSCs (Figure 5C). IL-17 levels were elevated in all mice at seven days compared to non-arthritis controls and remained persistently elevated in mice treated with BALB/c MSCs. There was a highly significant suppression of IL-17 levels in the serum levels of mice treated with syngeneic MSCs over the course of the study (Figure 5D). Serum IL-10 levels were elevated only at the seven day time point in MSC treated mice compared to non-arthritic controls (Figure 5E). Serum IL-4 was not detectable at either 7 or 20 days (results not shown).

\section{Discussion}

The ability of MSCs to suppress T cell proliferation and activation in vitro and their ability to promote repair suggest that they may be beneficial in treating inflammatory arthritis. However, studies using the CIA mouse model have been inconclusive with results varying from no benefit to exacerbation of disease [23,29-32]. Studies have used either MSC delivery at a single time point or multiple injections. We opted to use a single injection to directly compare the effect of single MSC strains and avoid confounding factors such as the development of an immune response to the MSC. Variations in the method of CIA induction, mouse strains used for MSC preparation, scoring systems, timing, cell number, and delivery makes it difficult to compare these published studies (Table 2) [48]. However, data suggest that any beneficial effect of MSCs may be mediated through the suppression of the Th1 and Th17 driven responses along with an increased antigen specific $\mathrm{T}$ regulatory cell response $[40,48,49]$. This study represents the first direct comparison of the effect of different murine MSC strains on the progression of CIA and does not demonstrate any protective effect of MSCs. Indeed, BALB/c MSCs clearly exacerbated disease both biochemically and clinically while FVB MSCs showed a trend towards increased disease severity with associated increases in host IL-1 $\beta$ production. Additionally, the disease scores seen in BALB/c treated mice were significantly higher than controls but did not reach statistical significance when compared to other MSC treated groups; this reinforces the lack of any amelioration of disease with MSCs and perhaps suggests a subtle subclinical negative impact on arthritis even in syngeneic MSC treated mice.

Several studies have demonstrated the immune privileged status of MSCs [24,33]. However, others have suggested that allogeneic MSCs can elicit a host immune response [50,51] and genetic disparity reduced the therapeutic benefit of MSCs in rat models of ischemic heart disease [52]. In particular, recent data in rat heart allograft studies demonstrated the presence of activated $\mathrm{T}$ cells in secondary lymphatic organs following the administration of MHC mismatched MSCs suggesting that allogeneic MSCs may elicit an immune response [53]. The ability of MSCs to suppress T cell proliferation has previously been demonstrated with Carboxyfluorescein succinimidyl ester (CFSE) staining [54]. Here, we focused on the effect of MSCs on cytokine production and have demonstrated a superior ability of syngeneic MSCs to suppress $\mathrm{T}$ cell responses in vitro with a decrease in pro-inflammatory cytokine production and 


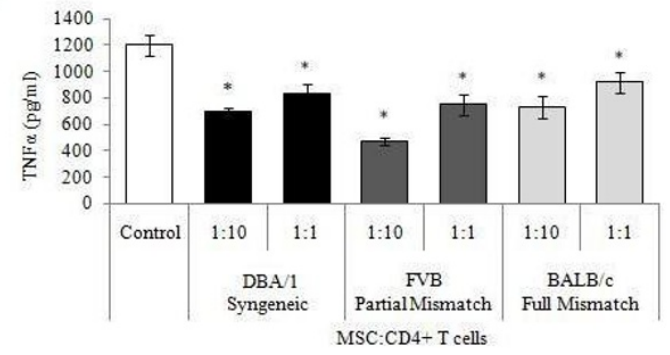

$\mathrm{C}$

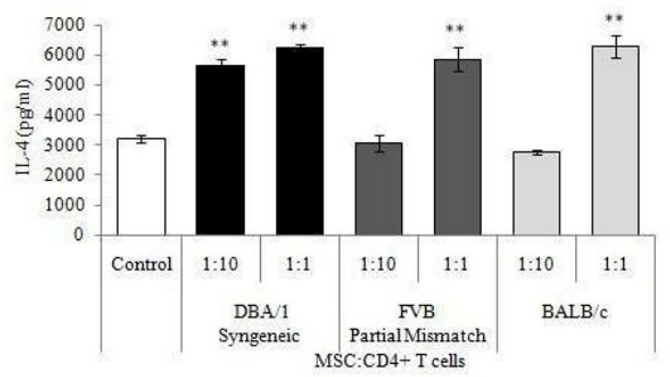

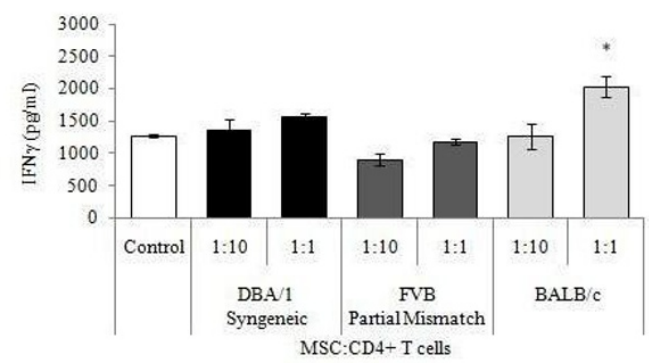

D

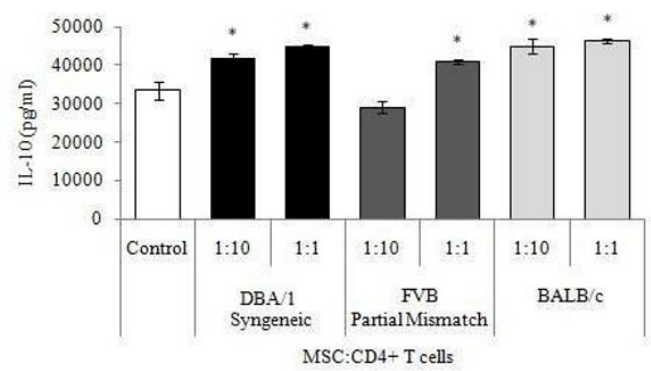

$\mathrm{E}$

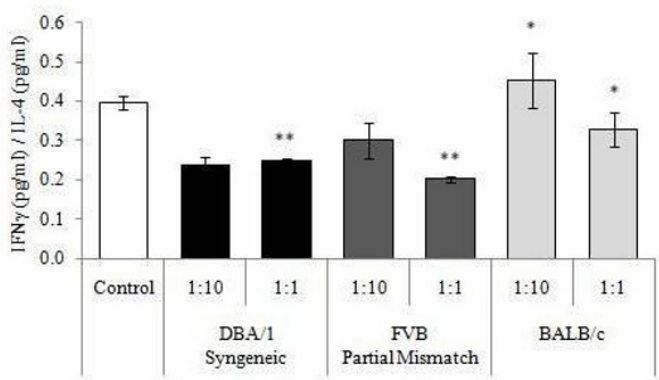

MSC:CD4+T cells

Figure 2 The effect of MSCs on cytokine production by CD4+ T cells. Control groups were CD4+ DBA/1 T cells stimulated with CD3/CD28 beads. DBA/1 (syngeneic), FVB (partially mismatched) or BALB/c (fully mismatched) MSCs were co-cultured with DBA/1 CD4+ T cells at a ratio of either 1:10 or 1:1. A, Co-culture with MSCs decreased TNF $\alpha$ secretion compared to controls independently of the genetic background of the MSC, ${ }^{*} P<0.05$ (2-way ANOVA). B, BALB/C MSCs increased IFN $\gamma$ production compared to controls at the ratio of 1:1, ${ }^{*} P<0.05$ (2-way ANOVA). C, DBA/1 MSCs augmented IL-4 production by CD4+ T cells at both ratios. This was also seen with FVB and BALB/C MSCs at the ratio of 1:1, ${ }^{*} P<0.01$ (2-way ANOVA). D, With the exception of FVB MSCs at a ratio of 1:10, the addition of MSCs resulted in an increase in IL-10 production, ${ }^{*} P<0.05$ (2-way ANOVA). E, IFNy:L-4 was taken to represent Th1:Th2 cytokine production by stimulated T cells. Co-culture with DBA/1 or FVB MSCs (1:1) significantly suppressed this ratio compared to controls, ${ }^{* * P}<0.01$ (2-way ANOVA). This was not seen when T cells were co-cultured with BALB/C MSCs. The Th1:Th2 ratio of T cells co-cultured with BALB/C MSCs was significantly higher than either the syngeneic or partially mismatched MSC groups, ${ }^{*} P<0.05$ (2-way ANOVA). Throughout $n=3$, data represents mean \pm standard deviation. ANOVA, analysis of variance; IFNy, interferon gamma; IL-10, interleukin 10; IL-4, interleukin 4; MSC, mesenchymal stem cells; n, number; Th, T helper cell; TNF $\alpha$, tumor necrosis factor alpha.

an alteration of the Th1:Th2 ratio. MHC mismatched allogeneic MSCs not only had less immunosuppressive effects in vitro compared to MHC matched cells but had a deleterious effect on disease progression in vivo. Fully mismatched BALB/c MSCs were the only cells which resulted in increased serum TNF $\alpha$ levels at day seven while all three stains of MSCs resulted in elevated serum IFN $\gamma$. By day 20 the effects on IFN $\gamma$ production were lost while only syngeneic DBA/1 cells resulted in a significant suppression of TNF $\alpha$ production compared to mice treated with vehicle alone. It was also demonstrated that all three strains of MSCs augmented the production of both IL- $1 \beta$ and IL-17. This effect was sustained in mice treated with either allogeneic cell with respect to IL-1 $\beta$ while only fully mismatched BALB/c MSCs had the effect of persistently elevating IL-17 levels by day 20 . Interestingly, this elevation in pro-inflammatory cytokines was significantly suppressed in mice treated with DBA/1 cells by day 20 after disease induction. Taken together these data demonstrate an early increase in systemic 

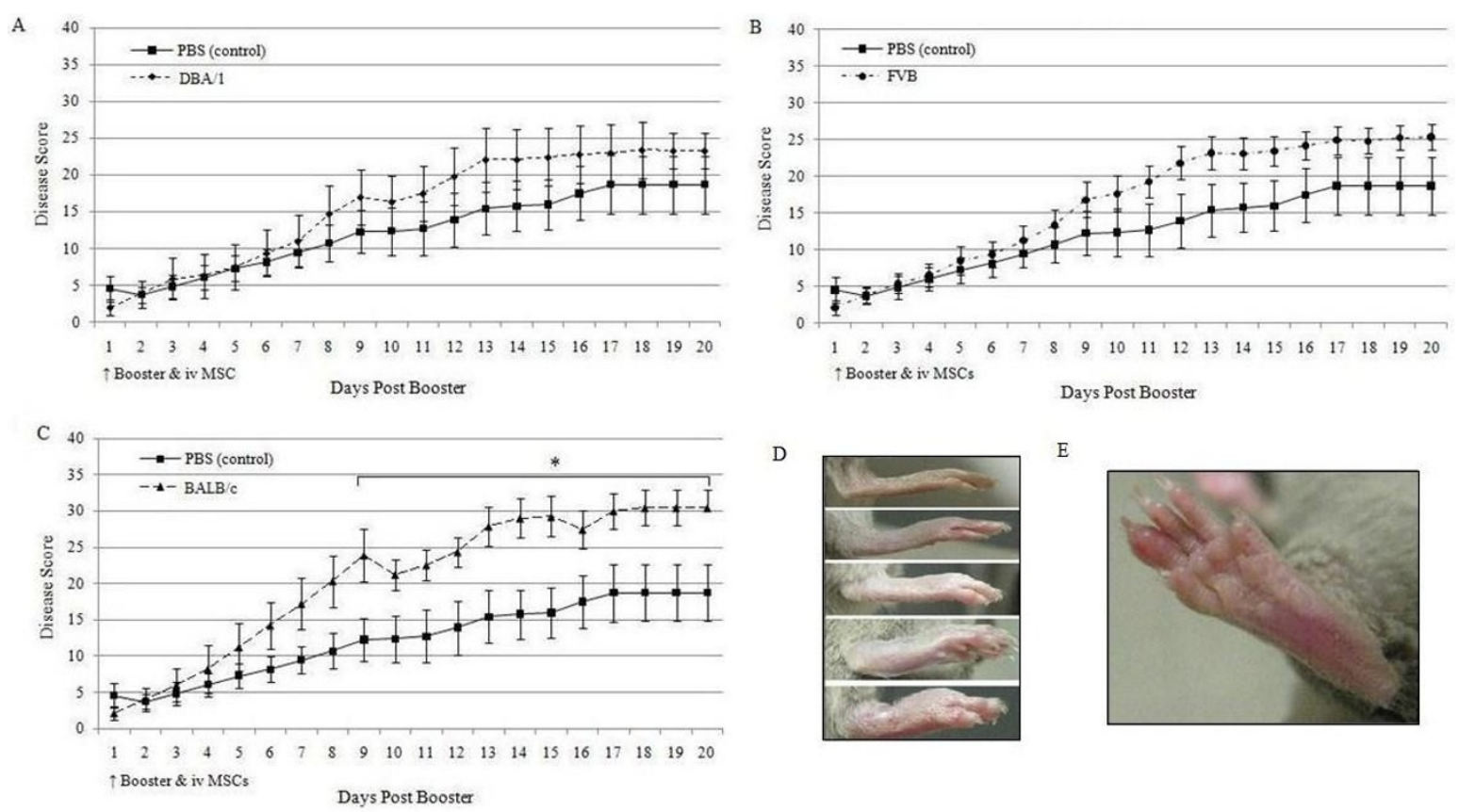

D

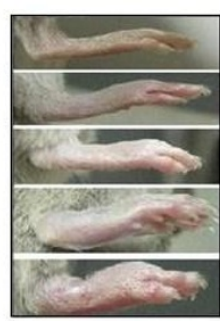

E

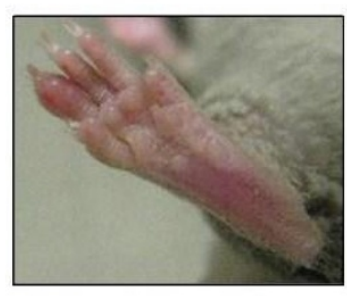

Figure 3 The effect of systemically infused MSCs on the progression of CIA in DBA/1 mice. A, Intravenous (iv) infusion of syngeneic DBA/ 1 MSCs at the time of booster immunization had no effect on disease progression. $\mathbf{B}$, While there appeared to be some worsening of disease progression after iv delivery of partially mismatched FVB MSCs, this did not reach statistical significance. C, Systemic delivery of fully mismatched BALB/C MSCs resulted in a significant exacerbation of disease progression compared to control groups which received vehicle alone. D, Representative images of swollen hind paws ranging from normal (top image) to grossly swollen (bottom image). E, Representative image of dactylitis in a single digit. All experiments were performed with $\mathrm{n}=12$ and results are represented as mean \pm standard deviation. ${ }^{*} P<0.05$, Shapiro Wilks testing for normal distribution followed by unpaired T and Mann Whitney U tests. CIA, collagen induced arthritis; MSC, mesenchymal stem cells; n, number.

inflammation in mice with arthritis treated with MSCs which is mediated predominantly through IFN $\gamma$, IL-1 $\beta$ and IL-17. While treatment with syngeneic MSCs is insufficient to suppress pro-inflammatory cytokine production at seven days, with time they have the effect of suppressing both IL-17 and IL-1 $\beta$ secretion. This may relate to increased survival of the cells in vivo or, given the clinical worsening of disease, a true deleterious effect of allogeneic MSCs on arthritis progression in an inflammatory environment. It has been reported that pre-stimulation of MSCs with IFN $\gamma$ may have the desirable effect of augmenting MSC immunosuppression in vitro [53]; however, it is clear that the inflammatory milieu of CIA does not facilitate this phenomenon. In vivo IL-4 levels were below detectable limits but a significant increase in IL-10 was demonstrated at day seven in all three treatment groups. While it has previously been shown that MSCs transduced to express IL-10 can ameliorate disease and the suppression of arthritis by adipose-derived MSCs was associated with increased synovial IL-10 levels [30,38], only a transient increase in this cytokine was demonstrated here. This was not sustained to 20 days and the impact of the expected MSC effect of increased IL-10 production was not sufficient to impact arthritis progression.

The conflicting results regarding the potential role of MSCs in arthritis have recently been highlighted [48]. By comparing MSCs from different murine strains in CIA under identical experimental conditions, these data go some way to addressing the conflicting results in previous studies. It has been demonstrated that, despite their low immunogenicity, the genetic mismatch between the MSC and host has a significant impact on the ability of MSCs to alter disease progression. Furthermore, the effect of MSCs on disease progression appears to be mediated predominantly by alterations in host IL-17 and IL- $1 \beta$ production.

\section{Conclusions}

The potential of MSCs to treat conditions such as arthritis may help us to meet the challenge of inducing remission and joint regeneration in patients with disease refractory to conventional treatment options. However, before translation to the bedside it is of fundamental importance that we fully understand pre-clinical data. While CIA is a reliable model of RA which continues to be used successfully in the development of therapeutics, 

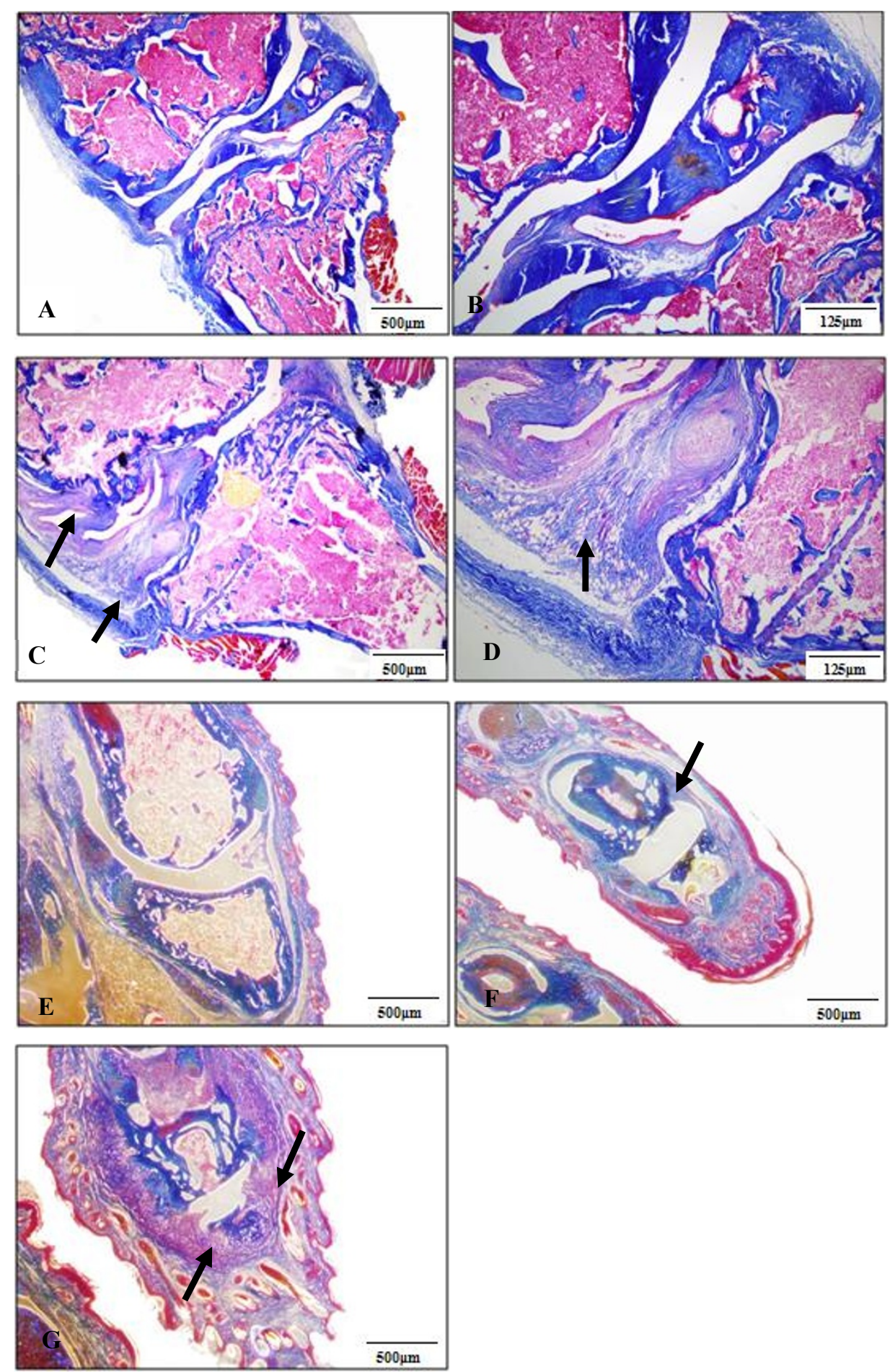

Figure 4 Histological analyses of knee joints. Fifty percent of the mice treated with vehicle control, syngeneic or partially mismatched MSCS had erosive disease compared to $70 \%$ of those treated with fully mismatched MSCs. A, B, A normal knee joint is illustrated (scale bar $500 \mu$ m and $125 \mu \mathrm{m}$, respectively). C, D, Synovial hypertrophy with erosive disease in the knee joint (black arrow) (scale bar $500 \mu \mathrm{m}$ and $125 \mu \mathrm{m}$, respectively). E, A control interphalangeal joint (IPJ) of the paw $(500 \mu \mathrm{m}), \mathbf{F}$, IPJ with synovial hypertrophy and early erosive disease (black arrow) $(500 \mu \mathrm{m})$ and G, a severely diseased IPJ with synovial hypertrophy and extensive erosive disease (black arrows); scale bars, 500 m. MSC, 
A

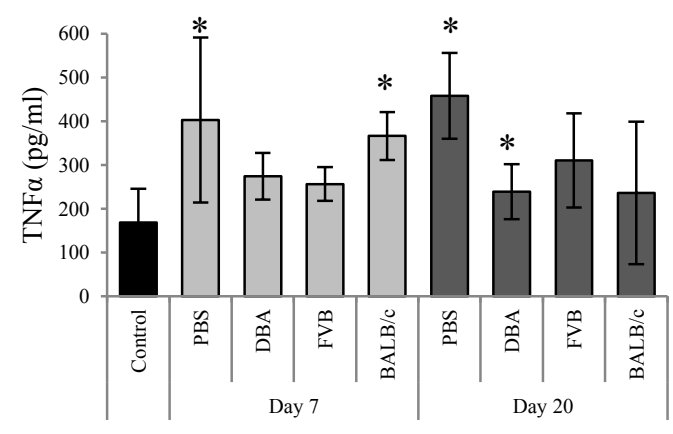

B

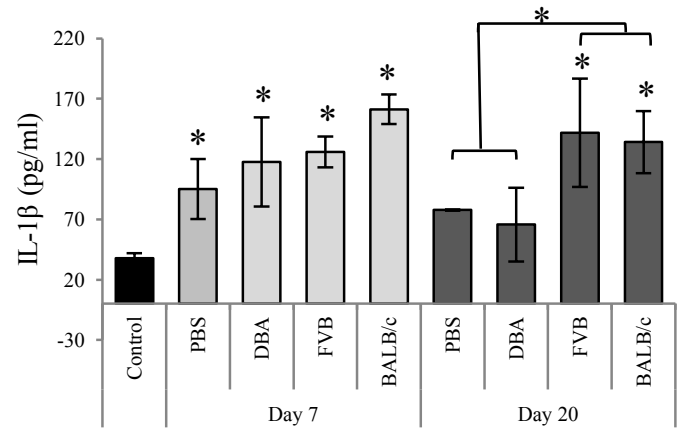

$\mathrm{D}$

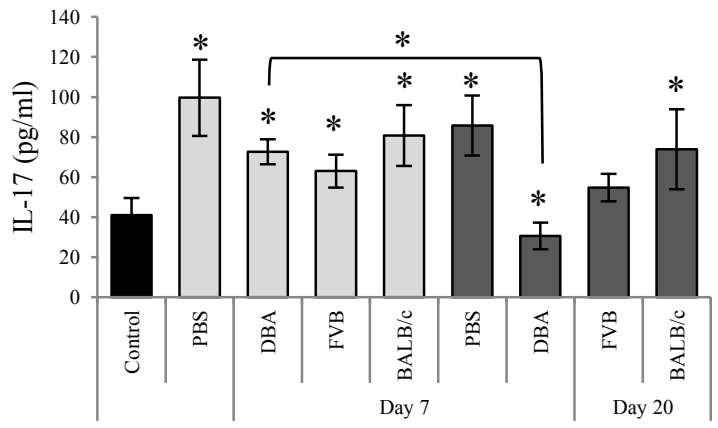

E

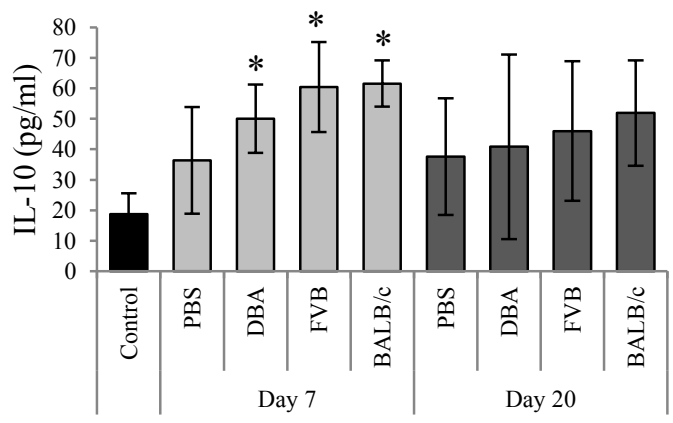

Figure 5 Serum levels of pro-inflammatory cytokines. A, At both 7 and 20 days after booster, and onset of CIA, TNF $\alpha$ levels were raised significantly in mice receiving vehicle alone (PBS) compared to pre-CIA control levels. TNF $\alpha$ levels were also elevated in mice treated with BALB/ c MSCs at seven days. At day 20 TNF $\alpha$ levels were significantly suppressed only in DBA/1 treated mice compared to the PBS group. B, IFN $\gamma$ levels were elevated in mice treated with any strain of MSC at seven days compared to pre-CIA controls. At 20 days there was a trend towards elevated IFN $\gamma$ levels in all groups but this did not reach statistical significance. C, At seven days IL-1 3 was elevated in all groups, $P<0.05$ (2-way ANOVA). At 20 days elevated levels persisted in mice treated with allogeneic MSCs; this was significant compared to groups treated with either PBS vehicle or syngeneic MSCs, $P<0.05$ (2-way ANOVA). D, IL-17 levels were significantly elevated on day seven in all treatment groups. By day 20, IL-17 levels were significantly raised only in vehicle treated mice and those treated with fully MHC mismatched allogeneic MSCS (BALB/C). The level of IL-17 in mice treated with syngeneic MSCS was significantly lower at day 20 than all other treatment groups at this timepoint and also when compared to DBA/1 treated mice at day seven, $P<0.05$ (2-way ANOVA). $\mathbf{E}$, At day seven there was an increase in IL-10 levels in all groups treated with MSCs compared to untreated controls. This effect was not seen at day 20. There were 12 mice per treatment group and all measurements were assayed in triplicate, ${ }^{*} P<0.05$ (2-way ANOVA). Data represents mean \pm standard deviation. ANOVA, analysis of variance; CIA, collagen induced arthritis; IFNy, interferon gamma; IL-1ß, interleukin 1 beta; IL-10, interleukin10; IL-17, interleukin 17; MHC, major histocompatibility complex; MSC, mesenchymal stem cells; PBS, phosphate-buffered saline; TNF $\alpha$, tumor necrosis factor alpha.

our data clearly demonstrate that a single injection of MSCs from different genetic backgrounds has disparate effects on disease progression as demonstrated in clinical scores and serum cytokine levels. This suggests that further studies looking at the effect of varying cell numbers and repeated delivery of MSCs are warranted in the future. These data need to be strongly considered when both analyzing and developing pre-clinical studies of inflammatory conditions if the transition of MSCs into clinical practice is to be successful. 
Table 2 Published studies of MSCs in CIA.

\begin{tabular}{|c|c|c|c|c|c|}
\hline Author, Year & MSC & Route & Cell number & Day of delivery & Outcome \\
\hline \multirow[t]{4}{*}{ Djouad, 2005} & $\mathrm{C} 3 \mathrm{H} 10 \mathrm{~T} 1 / 2$ & iv & $10^{6}$ & 0 & - \\
\hline & & & $10^{6}$ & 21 & - \\
\hline & & & $4 \times 10^{6}$ & 0 & - \\
\hline & & & $4 \times 10^{6}$ & 21 & Exacerbation \\
\hline Augello, 2007 & $\begin{array}{l}\text { BM C } 57 / B 1 / 10 \text { or } \\
\text { GFP transgenic }\end{array}$ & ip & $5 \times 10^{6}$ & 21 & Amelioration \\
\hline Choi, 2008 & $\mathrm{BM} \mathrm{DBA} / 1$ & iv & $10^{6}$ & $21,28,35$ & Delayed onset \\
\hline Gonzalez, 2009 & $\begin{array}{l}\text { hAdMSC } \\
\text { Ad DBA/1 } \\
\text { Ad C57/Bl6 }\end{array}$ & ip & $10^{6}$ & 5 days after disease onset & Amelioration \\
\hline Schurgers, 2010 & $\begin{array}{l}\text { BM DBA } 11 \text { WT or } \\
\text { IFN } \mathrm{KO}\end{array}$ & iv or ip & $10^{6}$ & $1,16,23$ & - \\
\hline
\end{tabular}

Ad, adipose derived; BM, bone marrow derived; h, human; ip, intraperitoneal; iv, intravenous; KO, knock out; WT, wild type.

\section{Abbreviations}

ANOVA: analysis of variance; ASC: adipose derived stem cell; CD: cluster of differentiation; CEM: complete expansion medium; CIA: collagen induced arthritis; Cll: type II collagen; (D)MEM: (Dulbecco's) modified Eagle's medium; ELISA: enyme-linked immunosorbent assay; FACS: fluorescence activated cell sorting; FBS: fetal bovine serum; GAG: glycosaminoglycan; IFNY: interferon gamma; IL: interleukin; MHC: major histocompatibility complex; MSC: mesenchymal stem cell; PBS: phosphate-buffered saline; P/S: penicillin and streptomycin; RA: rheumatoid arthritis; Th: T helper cell; TNFa: tumor necrosis factor alpha.

\section{Acknowledgements}

This research was supported by the Health Research Board under Grant No. CRT/2007/6 and Science Foundation Ireland under Grant Nos. 03/CE2/B312, 09/SRC/B1794 and SFI PI 06/IN.1/B652 (MDG).

\section{Author details}

${ }^{1}$ Regenerative Medicine Institute, National University of Ireland Galway, University Road, Galway, Ireland. ${ }^{2}$ Centre for Advanced Orthopaedic Studies, Beth Israel Deaconess Medical Centre, 330 Brookline Ave., RN 115, Boston, MA 02215, USA.

\section{Authors' contributions}

CS made significant contributions to study design, in vitro and in vivo experimental work, analysis of data, document preparation and submission. MM contributed to study design, analysis of data and document preparation. MG contributed to in vitro T cell stimulation studies. RP contributed to study design and in vivo data collection. CE contributed to study design, data analysis and document preparation. COF contributed to study design, histological analysis and document preparation. GS contributed to in vitro MSC work and flow cytometry. FB contributed to study design, data analysis and document preparation. All authors read and approved the final manuscript.

\section{Competing interests}

The authors declare that they have no competing interests.

Received: 8 February 2012 Revised: 29 May 2012

Accepted: 19 July 2012 Published: 19 July 2012

\section{References}

1. Fox DA, Gizinski A, Morgan R, Lundy SK: Cell-cell interactions in rheumatoid arthritis synovium. Rheum Dis Clin North Am 2010, 36:311-323.

2. Choy EH, Panayi GS: Cytokine pathways and joint inflammation in rheumatoid arthritis. N Engl J Med 2001, 344:907-916.

3. Firestein GS: Evolving concepts of rheumatoid arthritis. Nature 2003, 423:356-361.

4. Furst DE: Development of TNF inhibitor therapies for the treatment of rheumatoid arthritis. Clin Exp Rheumatol 2010, 28(Suppl 59):S5-12.
5. Emery P, Breedveld FC, Hall S, Durez P, Chang DJ, Robertson D, Singh A Pedersen RD, Koenig AS, Freundlich B: Comparison of methotrexate monotherapy with a combination of methotrexate and etanercept in active, early, moderate to severe rheumatoid arthritis (COMET): a randomised, double-blind, parallel treatment trial. Lancet 2008, 372:375-382

6. Breedveld FC, Weisman MH, Kavanaugh AF, Cohen SB, Pavelka K, van Vollenhoven R, Sharp J, Perez JL, Spencer-Green GT: The PREMIER study: a multicenter, randomized, double-blind clinical trial of combination therapy with adalimumab plus methotrexate versus methotrexate alone or adalimumab alone in patients with early, aggressive rheumatoid arthritis who had not had previous methotrexate treatment. Arthritis Rheum 2006, 54:26-37.

7. Papagoras C, Voulgari PV, Drosos AA: Strategies after the failure of the first anti-tumor necrosis factor alpha agent in rheumatoid arthritis. Autoimmun Rev 2010, 9:574-582.

8. Finckh A, Ciurea A, Brulhart L, Kyburz D, Moller B, Dehler S, Revaz S, Dudler J, Gabay C: B cell depletion may be more effective than switching to an alternative anti-tumor necrosis factor agent in rheumatoid arthritis patients with inadequate response to anti-tumor necrosis factor agents. Arthritis Rheum 2007, 56:1417-1423.

9. Genovese MC, McKay JD, Nasonov EL, Mysler EF, da Silva NA, Alecock E, Woodworth T, Gomez-Reino JJ: Interleukin-6 receptor inhibition with tocilizumab reduces disease activity in rheumatoid arthritis with inadequate response to disease-modifying antirheumatic drugs: the tocilizumab in combination with traditional disease-modifying antirheumatic drug therapy study. Arthritis Rheum 2008, 58:2968-2980.

10. Doncarli A, Stasiuk LM, Fournier C, Abehsira-Amar O: Conversion in vivo from an early dominant Th0/Th1 response to a Th2 phenotype during the development of collagen-induced arthritis. Eur J Immunol 1997, 27:1451-1458.

11. Billiau A, Matthys P: Collagen-induced arthritis and related animal models: how much of their pathogenesis is auto-immune, how much is auto-inflammatory? Cytokine Growth Factor Rev 2011, 22:339-344.

12. Shahrara S, Pickens SR, Dorfleutner A, Pope RM: IL-17 induces monocyte migration in rheumatoid arthritis. J Immunol 2009, 182:3884-3891.

13. Dong C: Regulation and pro-inflammatory function of interleukin-17 family cytokines. Immunol Rev 2008, 226:80-86.

14. Lubberts E, Koenders Ml, Oppers-Walgreen B, van den Bersselaar L, Coenende Roo CJ, Joosten LA, van den Berg WB: Treatment with a neutralizing anti-murine interleukin-17 antibody after the onset of collagen-induced arthritis reduces joint inflammation, cartilage destruction, and bone erosion. Arthritis Rheum 2004, 50:650-659.

15. Lubberts E, Joosten LA, Oppers B, van den Bersselaar L, Coenen-de Roo CJ, Kolls JK, Schwarzenberger P, van de Loo FA, van den Berg WB: IL-1independent role of IL-17 in synovial inflammation and joint destruction during collagen-induced arthritis. J Immunol 2001, 167:1004-1013.

16. Kim JM, Jeong JG, Ho SH, Hahn W, Park EJ, Kim S, Yu SS, Lee YW: Protection against collagen-induced arthritis by intramuscular gene therapy with an expression plasmid for the interleukin-1 receptor antagonist. Gene Ther 2003, 10:1543-1550. 
17. English K, Barry FP, Mahon BP: Murine mesenchymal stem cells suppress dendritic cell migration, maturation and antigen presentation. Immunol Lett 2008, 115:50-58.

18. Corcione A, Benvenuto F, Ferretti E, Giunti D, Cappiello V, Cazzanti F, Risso M, Gualandi F, Mancardi GL, Pistoia V, Ucelli A: Human mesenchymal stem cells modulate B-cell functions. Blood 2006, 107:367-372.

19. Najar M, Raicevic G, Boufker HI, Fayyad Kazan H, De Bruyn C, Meuleman N, Bron D, Toungouz M, Lagneaux L: Mesenchymal stromal cells use PGE2 to modulate activation and proliferation of lymphocyte subsets: combined comparison of adipose tissue, Wharton's Jelly and bone marrow sources. Cell Immunol 2010, 264:171-179.

20. Barry FP, Murphy JM: Mesenchymal stem cells: clinical applications and biological characterization. Int J Biochem Cell Biol 2004, 36:568-584.

21. Di Nicola M, Carlo-Stella C, Magni M, Milanesi M, Longoni PD, Matteucci P, Grisanti S, Gianni AM: Human bone marrow stromal cells suppress Tlymphocyte proliferation induced by cellular or nonspecific mitogenic stimuli. Blood 2002, 99:3838-3843.

22. Djouad F, Plence P, Bony C, Tropel P, Apparailly F, Sany J, Noel D, Jorgensen $C$ : Immunosuppressive effect of mesenchymal stem cells favors tumor growth in allogeneic animals. Blood 2003, 102:3837-3844.

23. Cui L, Yin S, Liu W, Li N, Zhang W, Cao Y: Expanded adipose-derived stem cells suppress mixed lymphocyte reaction by secretion of prostaglandin E2. Tissue Eng 2007, 13:1185-1195.

24. Tse WT, Pendleton JD, Beyer WM, Egalka MC, Guinan EC: Suppression of allogeneic T-cell proliferation by human marrow stromal cells: implications in transplantation. Transplantation 2003, 75:389-397.

25. Aggarwal S, Pittenger MF: Human mesenchymal stem cells modulate allogeneic immune cell responses. Blood 2005, 105:1815-1822.

26. Griffin MD, Ritter T, Mahon BP: Immunological aspects of allogeneic mesenchymal stem cell therapies. Hum Gene Ther 2010, 21:1641-1655.

27. English K, French A, Wood KJ: Mesenchymal stromal cells: facilitators of successful transplantation? Cell Stem Cell 2010, 7:431-442.

28. De Bari C, Dell'Accio F, Tylzanowski P, Luyten FP: Multipotent mesenchymal stem cells from adult human synovial membrane. Arthritis Rheum 2001, 44:1928-1942.

29. Zheng $Z H$, Li XY, Ding J, Jia JF, Zhu P: Allogeneic mesenchymal stem cell and mesenchymal stem cell-differentiated chondrocyte suppress the responses of type II collagen-reactive T cells in rheumatoid arthritis. Rheumatology (Oxford) 2008, 47:22-30.

30. Gonzalez-Rey E, Gonzalez MA, Varela N, O'Valle F, Hernandez-Cortes P, Rico L, Buscher D, Delgado M: Human adipose-derived mesenchymal stem cells reduce inflammatory and $T$-cell responses and induce regulatory T cells in vitro in rheumatoid arthritis. Ann Rheum Dis 2010, 65:241-248.

31. Alm JJ, Koivu HM, Heino TJ, Hentunen TA, Laitinen S, Aro HT: Circulating plastic adherent mesenchymal stem cells in aged hip fracture patients. $J$ Orthop Res 2010, 28:1634-1642.

32. Loebinger MR, Kyrtatos PG, Turmaine M, Price AN, Pankhurst $Q$, Lythgoe MF, Janes SM: Magnetic resonance imaging of mesenchymal stem cells homing to pulmonary metastases using biocompatible magnetic nanoparticles. Cancer Res 2009, 69:8862-8867.

33. Le Blanc K, Rasmusson I, Gotherstrom C, Seidel C, Sundberg B, Sundin M, Rosendahl K, Tammik C, Ringden O: Mesenchymal stem cells inhibit the expression of CD25 (interleukin-2 receptor) and CD38 on phytohaemagglutinin-activated lymphocytes. Scand J Immunol 2004, 60:307-315.

34. Potian JA, Aviv H, Ponzio NM, Harrison JS, Rameshwar P: Veto-like activity of mesenchymal stem cells: functional discrimination between cellular responses to alloantigens and recall antigens. J Immunol 2003, 171:3426-3434.

35. Majumdar MK, Keane-Moore M, Buyaner D, Hardy WB, Moorman MA, McIntosh KR, Mosca JD: Characterization and functionality of cell surface molecules on human mesenchymal stem cells. J Biomed Sci 2003, 10:228-241.

36. Djouad F, Fritz V, Apparailly F, Louis-Plence P, Bony C, Sany J, Jorgensen C, Noel D: Reversal of the immunosuppressive properties of mesenchymal stem cells by tumor necrosis factor alpha in collagen-induced arthritis. Arthritis Rheum 2005, 52:1595-1603.

37. Augello A, Tasso R, Negrini SM, Cancedda R, Pennesi G: Cell therapy using allogeneic bone marrow mesenchymal stem cells prevents tissue damage in collagen-induced arthritis. Arthritis Rheum 2007, 56:1175-1186.
38. Choi JJ, Yoo SA, Park SJ, Kang YJ, Kim WU, Oh IH, Cho CS: Mesenchymal stem cells overexpressing interleukin-10 attenuate collagen-induced arthritis in mice. Clin Exp Immunol 2008, 153:269-276.

39. Schurgers E, Kelchtermans H, Mitera T, Geboes L, Matthys P: Discrepancy between the in vitro and in vivo effects of murine mesenchymal stem cells on T-cell proliferation and collagen-induced arthritis. Arthritis Res Ther 2010, 12:R31.

40. Park MJ, Park HS, Cho ML, Oh HJ, Cho YG, Min SY, Chung BH, Lee JW, Kim HY, Cho SG: Transforming growth factor beta-transduced mesenchymal stem cells ameliorate experimental autoimmune arthritis through reciprocal regulation of Treg/Th17 cells and osteoclastogenesis. Arthritis Rheum 2011, 63:1668-1680.

41. Bouffi C, Bony C, Courties G, Jorgensen C, Noel D: IL-6-dependent PGE2 secretion by mesenchymal stem cells inhibits local inflammation in experimental arthritis. PLOS One 2010, 5:e14247.

42. Peister A, Mellad JA, Larson BL, Hall BM, Gibson LF, Prockop DJ: Adult stem cells from bone marrow (MSCs) isolated from different strains of inbred mice vary in surface epitopes, rates of proliferation, and differentiation potential. Blood 2004, 103:1662-1668.

43. Zhu $H$, Guo ZK, Jiang XX, Li H, Wang XY, Yao HY, Zhang Y, Mao N: A protocol for isolation and culture of mesenchymal stem cells from mouse compact bone. Nat Protoc 2010, 5:550-560.

44. Neuhuber B, Gallo G, Howard L, Kostura L, Mackay A, Fischer I: Reevaluation of in vitro differentiation protocols for bone marrow stromal cells: disruption of actin cytoskeleton induces rapid morphological changes and mimics neuronal phenotype. J Neurosci Res 2004, 77:192-204.

45. Sterchi DL, Eurell JA: A new method for preparation of undecalcified bone sections. Stain Technol 1989, 64:201-205.

46. Sung JH, Yang HM, Park JB, Choi GS, Joh JW, Kwon CH, Chun JM, Lee SK, Kim SJ: Isolation and characterization of mouse mesenchymal stem cells. Transplant Proc 2008, 40:2649-2654.

47. Malfait AM, Williams RO, Malik AS, Maini RN, Feldmann M: Chronic relapsing homologous collagen-induced arthritis in DBA/1 mice as a model for testing disease-modifying and remission-inducing therapies. Arthritis Rheum 2001, 44:1215-1224.

48. Macdonald Gl, Augello A, De Bari C: Mesenchymal stem cells: reestablishing immunological tolerance in autoimmune rheumatic diseases. Arthritis Rheum 2011, 63:2547-2557.

49. Liu Y, Mu R, Wang S, Long L, Liu X, Li R, Sun J, Guo J, Zhang X, Yu P Li C, Liu X, Huang Z, Wang D, Li H, Gu Z, Liu B, Li Z: Therapeutic potential of human umbilical cord mesenchymal stem cells in the treatment of rheumatoid arthritis. Arthritis Res Ther 2010, 12:R210.

50. Badillo AT, Beggs KJ, Javazon EH, Tebbets JC, Flake AW: Murine bone marrow stromal progenitor cells elicit an in vivo cellular and humoral alloimmune response. Biol Blood Marrow Transplant 2007, 13:412-422.

51. Eliopoulos N, Stagg J, Lejeune L, Pommey S, Galipeau J: Allogeneic marrow stromal cells are immune rejected by MHC class I- and class IImismatched recipient mice. Blood 2005, 106:4057-4065.

52. Huang XP, Sun Z, Miyagi Y, McDonald Kinkaid H, Zhang L, Weisel RD, Li RK: Differentiation of allogeneic mesenchymal stem cells induces immunogenicity and limits their long-term benefits for myocardial repair. Circulation 2010, 122:2419-2429.

53. Eggenhofer E, Steinmann JF, Renner P, Slowik P, Piso P, Geissler EK, Schlitt HJ, Dahlke MH, Popp FC: Mesenchymal stem cells together with mycophenolate mofetil inhibit antigen presenting cell and T cell infiltration into allogeneic heart grafts. Transpl Immunol 2011, 24:157-163.

54. Duffy MM, Pindjakova J, Hanley SA, McCarthy C, Weidhofer GA, Sweeney EM, English K, Shaw G, Murphy JM, Barry FP, Mahon BP, Belton O, Ceredig R, Griffin MD: Mesenchymal stem cell inhibition of T-helper 17 cell- differentiation is triggered by cell-cell contact and mediated by prostaglandin E2 via the EP4 receptor. Eur J Immunol 2011, 41:2840-2851.

\section{doi:10.1186/ar3916}

Cite this article as: Sullivan et al:: Genetic mismatch affects the immunosuppressive properties of mesenchymal stem cells in vitro and their ability to influence the course of collagen-induced arthritis. Arthritis Research \& Therapy 2012 14:R167. 